\title{
The effect of Saffron aqueous extract on hepatocellular carcinoma rat model
}

\section{Nabila Zein}

Biochemistry Division, Chemistry Department Faculty of Science, Zagazig University, Egypt

\begin{tabular}{l}
\hline A R T I C L E I N F O \\
\hline Article history: \\
Key words:- saffron, DEN, \\
$\mathrm{CCl}_{4}, \mathrm{HCC}$, apoptosis
\end{tabular}

A B S T R A C T
The aim of this study was to investigate the tumor suppressive effects
of saffron in an experimental hepatocellular carcinoma (HCC) model
in rats. Thirty rats were included in this study and divided into:-
Control group : Rats which receive distilled water only. HCC group :
induced by diethylnitrosamine (DEN) and $\mathrm{CCl}_{4}$ only. Saffron group :
Rats were administered orally saffron respectively 2 weeks prior to
HCC initiation and continued for 6 weeks. The effect of saffron on
ALT and AST activity and albumin level were studied also TGF-beta
level and the TAC level were estimated and induction of apoptosis
was determined by histopathological studies. Treatment with saffron
was significantly decreased the activities of ALT and AST also
increased the albumin level, decreased the TGF-beta level and
increased the TAC level, it also reduced the elevation in the number
and the incidence of hepatic dyschromatic nodules. Moreover,
treatment with saffron extract brought significant restoration of the
hematological parameters to values that were comparable to those of
the negative control group, it also enhances the liver and kidney
health, this study provides evidence that saffron exerts anti-oxidant,
chemoperventive effect against liver cancer through induction of
apoptosis as appeared in histopathological studies

\section{INTRODUCTION}

Hepatocellular carcinoma is the fifth most common cancer and the third leading cause of cancer mortality in the world[1]. Most cases of HCC as a result of either viral hepatitis infection (hepatitis B virus or hepatitis $\mathrm{C}$ virus), metabolic toxin such as alcohol or aflotoxin[2]. Other factors that contribute to the formation of $\mathrm{HCC}$ include exposure to environmental carcinogens, Iron overload and fatty liver disease[3]. Current studies have shown the dietary factors such as carotenoids and antioxidants play a key role in the development of cancers[4]. Anticancer activity and protective effects of natural products has extensively been studied such the activity of the saffron against cancer has been also reported[5]. Saffron, the dried stigma of Crocus Sativus L. belonging to The Iridaceae Family cultivated in Iran, Europe, Turkey, Asia, India, China and Algeria[6]. Saffron has been widely used as a herbal medicine, Spice, food coloring and a flavoring agent since ancient times. It can increase the bioavailability and enhance absorption of other drugs[6]. Over along period of time, many health benefits of saffron have been known in traditional medicine and it has been used in various aliments including bronchospasms, asthema menstruation, insomenia, pain relief and cardiovascular disease[7]. In the last years, scientists have focused on pharmacological activity of saffron and its purified constituents. Results of these in vivo and in vitro studies have demonstrated anticancer, antioxidant, anti-convulsant, anti-depressent, 
anti-anxiety and memory improvement properties of this golden spice[8]. In this study, the potential antitumor effect of saffron was tested.

\section{Materials and Methods :- Chemicals :}

Diethylnitrosamine (DEN), carbontetrachloride $\left(\mathrm{CCl}_{4}\right)$ were purchased from Sigma Alderish .

\section{Plant material :}

Crocus sativus L. stigmata (saffron) were purchased from the local market at Cairo, Egypt. The plant sample were kindly identified and proved by Herbarium unit of Potany Department faculty of Science Zagazig University.

\section{Aqueous extract preparation :}

$270 \mathrm{gm}$ of saffron soaked in 4.5 liter distilled water for 3 days in the fridge and then filtered for 24 hours, this aqueous extract was lyophilized ( freez-drying) by lyophilizer[5].

\section{Animals:}

Adult male Spraguse-Dawely rats weighing 150-200 gm were purched from Animal House of the National Research Centre ,Dokki, Giza, Egypt . They were kept individually in stainless steel wire bottomed cages at room temperature. Rats had free access to food and water.

\section{Experimental design :-}

Animals were randomly divided to three groups of thirty rats as follow:

Group 1: Control group, Rats were treated with distilled water $(5 \mathrm{ml} / \mathrm{kg}$ weight $)$

Group 2: HCC group, Rats induced by $\mathrm{DEN}$ and $\mathrm{CCl}_{4}$ (DEN group).

Group 3: Saffron group, Rats were treated by oral gavage with saffron ( $300 \mathrm{mg}$ $/ \mathrm{kg}$ ) daily[9] 2 weeks prior to $\mathrm{HCC}$ initiation and continued for 6 weeks (saff. Group) .

The protocols for animal experimentation and the handling of animals were in accordance with the animal welfare act and the guide for the care and use of laboratory animals established by Zagazig university, Zagazig-Egypt

\section{Preparation of HCC model :-}

Hepatocarcinogenesis was induced in rats by injection of a single intraperitoneal dose of diethylnitrosamine at a dose of 200 $\mathrm{mg} / \mathrm{kg}$ body weight followed by weekly subcutaneous injections of $\mathrm{CCl}_{4}$ at a dose of $3 \mathrm{ml} / \mathrm{kg}$ body weight for 6 weeks[10].

\section{Sampling of blood :-}

At the end of the experiment, the blood samples were collected from the retroorbital venous plexus and direct cardiac puncture, under ether anesthesia samples for biochemical analysis into plain sample tubes.

Serum was separated by centrifugation at 600x $\mathrm{g}$ for $10 \mathrm{~min}$ and were stored in the $80{ }^{\circ} \mathrm{C}$ freezer before they were analyzed.

Whole blood used for haematogram was collected into tubes containing the anticoagulant, ethylene diamine tetraacetic acid (EDTA)

\section{Biochemical analysis :-}

1- Determination of plasma aspartate and alanine aminotransferases activities (AST \&ALT) by Young[11] Reitman and Frankel[12], serum albumin level by Satoh [13], total antioxidant capacity level (TAC) by Koracevic et al., [14] and transforming growth factor -beta (TGFbeta) level by Oki et al.[15] and haematological parameters were determined by auto haematology analyzer (Diatron Abacus 380)

\section{Histopathological analysis :-}

The harvested liver tissues were fixed in $10 \%$ formaline then the specimens were dehydrated in a graded series of ethanol cleared in xylene and embedded in paraffin wax. Tissue blocks were sectioned into 4.0 $\mu \mathrm{m}$ thick using rotary microtome. 
Sections were stained by hematoxylin and eosin. Stained sections were examined by light microscope[16].

\section{Statistical anaylsis :-}

Statistical analysis of data was performed by using SPSS 14.0 version T-test (2tailed) was applied to compare between groups and one-way analysis of variance (ANOVA) followed by post-hoc test using Graphpad Prismm-5 software.

Numerical data were expresses as mean \pm $\mathrm{SD}, \mathrm{P}$ values $<0.05$ were considered to be statistically significant[17].

\section{Results :-}

\section{-Extraction of plant:}

Saffron (270 gm) after undergoing extraction yielded deeply red paste of 33 gm.

\section{-Effect on ALT, AST activities \&Alb levels:}

Serum levels of alanine aminotransferase and aspartate aminotransferase are usually used as indicators of hepatocellular damage.In this study, the changes in their serum level in the different test groups were measured to assess the effect of DEN alone and DEN with saffron on liver integrity. Due to the hepatocellular damaging effect of DEN, significant increase in rat serum ALT \& AST levels was detectable in DEN- treated group compared to the healthy control group. On the other hand, saffron treatment of animals that adiminstered DEN resulted in a significant reduction of the DENinduced elevation of ALT / AST serum levels , as well as elevation in Alb level as presented in table (1) and fig.(1) and fig. (2).

\section{-Effect on total antioxidant capacity and tumor growth factor -beta}

In the current study, the DEN with $\mathrm{CCl}_{4}$ induced HCC showed significant decrease in TAC in comparison to control group and overexpression of TGF-beta as presented in table (2) and fig.(3).

\section{-Hematological result :}

There was significant differences in $\mathrm{RBC}, \mathrm{WBC}$ and platlets counts and $\mathrm{Hb}$ concentration when comparing DENtreated group compared to the DEN with saffron group as presented in table (3) and fig.(4) and fig.(5).

\section{-Histopathological study :}

Histopathological examination for normal liver tissue showed central normal hepatocytes with central nuclei and eosinophilic cytoplasm

Whereas dysplastic foci have cellular atypia and tissue disorganization were seen scattered with hepatic paranchyma in rats treated with DEN- $\mathrm{CCl}_{4}$ alone, the formentioned dysplastic cells were large with vaculated nuclei. The latter were hyperchromatic with fragmented periphery situated chromatin and prominent nodules beside mitotic figure, the remaining hepatic parenchyma suffered from different types of cell injuries varied from acute cell swelling diffuse steatosis to coagulative necrosis. Congested blood vessels, focal hemorrhage and hemosedrosis were evident. However, in saffron-treated group, a few scattered hepatic foci from dysplastic cells with inflammatory reactions were observed. the majority of cells which exhibited neoplastic features suffered from apoptosis. Focal microsteatosis of some hepatic cells have periphery lobular zone distributions without necrotic changes in the hepatic parenchyma were common .A few strands collagen deposits containing mononuclear cells and bile canaliculi could be seen in portal area and interlobular tissues as presented in figs.(6,7 and 8$)$ and by comparing the histopathological studies of kidneys of DEN group and saff. Group treatment with saffron reduced most of the pathological alterations occurred . 


\section{Discussion:-}

HCC is the main form of liver cancer and classified as the fifth leading cause of cancer mortality due to it's bad prognosis[18].

The common denominator in HCC of different etiology is the induction of oxidative stress by inflammatory cells resulting in chronic hepatic injury and cell death followed by oncogenic transformation of surviving hepatocytes and compensatory proliferation that lead to tumorgenesis[19].

Diethylnitrosamine (DEN) is a representive chemical of a family of carcinogenic n-nitrosocompounds . Nnitroso compounds can acts as alkylating agents either directly or after metabolic activation by cytochrome P450 enzymes which are the key enzymes in tumorgensis[20].

DEN plays an important role in induction of hepatic carcinogenesis via increased generation of ROS and decreased antioxidant enzymes in liver[21].

ROS play a major role in tumor promotion through interaction with critical macromolecules including lipids causing lipid peroxidation and DNA causing DNA adducts[22].

The current results were in accordance with Femke [23] who showed that treatment with DEN induced DNA damage, mutation and induction of HCC. It was revealed by Yan [24] that treatment with DEN induced cell proliferation associated with DNA adducts and lipid peroxidation.

According to the study of Fengyuan[25], it isn't recommended that researchers should use DEN alone for the development of HCC rat model, because the long modeling time that DEN injection would increase the process and increase both time and cost, one of the ways to shorten the modeling time is combining DEN with $\mathrm{CCl}_{4}$ [12]. So, we combined DEN with $\mathrm{CCl}_{4}$ to induce HCC rat models.

$\mathrm{CCl}_{4}$ which is well known hepatotoxin that is widely used to induce toxic liver injury in a range of laboratory animals, $\mathrm{CCl}_{4}$ induced hepatotoxicity is believed to involve two phases, the initial phase involves the metabolism of $\mathrm{CCl}_{4}$ by CYP450 to $\mathrm{CCl}_{3}$ and /or $\mathrm{CCl}_{3} \mathrm{OO}$ which lead to membrane lipid peroxidation and finally to cell necrosis. The second phase of $\mathrm{CCl}_{4}$ induced hepatotoxicity involves the activation of kupffer cells which is accompanied by the production of proinflammatory mediators[26]. In agreement, Ghada et al., [27] demonsterated the alteration of biochemical markers,Hepatic antioxidant status and hepatic nucleic acid content may therefore manifestation of oxidative stress and cellular DNA damage caused by $\mathrm{CCl}_{4}$. Saffron, a spice and a food colorant present in the dry stigmas of the plant (Crocus Sativus L. ) has been used as a herbal remedy for various aliments including cancer by the ancient Arabian,Indian and Chinese cultures[28]. Most investigations present verifications that saffron exert an important chemopreventive effect against liver cancer due to inhibition of cell proliferation and induction of apoptosis[29].

The exact mechanisms underlying this effect are largely unknown. Different hypotheses for anticarcinogenic and antitumor effects of saffron and its ingredients have been proposed including inhibition of DNA and RNA synthesis not protein, ability of scavenge of free radicals, involvement in the metabolic of conversion of carotenoids to retenoids, mediation of interactionof carotenoids with topoisomerase 2 , an enzyme involved in cellular DNA-protien interaction and promotion of interaction mediated via lectins[30]. Several studies demonstrated the role of oxidative stress in liver pathogenesis and proved the role of natural antioxidants in its amelioration.

To assess such stress, some biochemical parameters are being evaluated like ALT and AST which give an indiction about liver cell damage.In the present study, we 
showed that treatment with saffron decrease the levels of ALT \&AST . This decrease suggests risk reduction of oxidative stress and pathological conditions associated with liver damage[31].

In agreement, Tawfic [32]demonstrated that levels of ALT \& AST were decreased because of treatment with crocin which is the main constituent of the saffron. However, saffron treatment as described before was yet not able to normalize ALT \& AST values as their levels were still higher than these of the healthy control group. [32].

In this context, When Reham et al., [33] used acurcumin as an anticancer for HCC, they reported that curcumin decreased level of these enzymes and the decreased the level of oxidative stress.

Significant decrease in serum albumin had been associated with active cirrhosis and biliary liver damages [34]. In our results the level of albumin was decreased in HCC group and shifted towards the normal values by saffron treatment which reflect the antioxidant activity and hepatoprotective effect of saffron .

This is in agreemnet with Moustafa [35] who stated that the pre-treatment by coriander and silymarin restores serum albumin level and maintained the antioxidant status in rats with liver fibrosis.

Also Nasir, [36] in another study stated that treatment of aqueous leaf extract of Cnidoscolus aconitifoliu can make the restoration of the level of albumin indicating the hepatoprotective nature of Cnidoscolus aconitifoliu.

A communal connection among chronic liver injury and hepatic fibrosis and liver cancer might be linked to oxidative stress.[31]

Living organisms have developed a multiple antioxidant network to counteract reactive species that are harmful to life. So, it is important to measure antioxidants. The possible interaction among different antioxidants in vivo could also sort the measurement of any singular antioxidant less descriptive of the whole antioxidant status.In the current study, the DEN with $\mathrm{CCl}_{4}$ induced $\mathrm{HCC}$ showed significant decrease in TAC in comparison to control group, that finding came in accordance with that of Mehmet[37], who stated that TAC was significantly lower in fibrotic group than in normal one.

As shown in Table (2) and Fig(3) TGF- $\beta$ has various profibrogenic and also antiinflammatory, immunosuppressive effects. The constancy of these actions is necessary for keeping tissue homeostasis and an atypical expression of TGF-beta is participated in a series of disease processes in the liver, TGF- $\beta$ is also an important negative controller of proliferation and an enhancer to apoptosis [38]. The comprehensive pathophysiologic significance of TGF-beta suggests its measurement in blood as a diagnostic tool. Abnormal expression of TGF- $\beta$ is accompanied by a number of diseases processes including fibrosis and cancer[39].

As liver cancer is accompanied by an overexpression of TGF-beta ${ }^{[40]}$, our results in table(2) and fig.(3) revealed over expression in TGF- $\beta$ level in HCC group as compared with control and saffron groups.

Hematological studies carried out to make clearer picture of any liver disease and it is cleared from our results that saffron restored the hematological markers nearly to normal levels as presented in table (3) and fig.(4) and fig.(5).

The histological studies were carried basically to support the results obtained from serum enzymes assays.

The histological results obtained in the current study, showed that DEN caused gross structural alterations in rat liver,with dysplastic foci have cellular atypia and tissue organization were seen scattered with hepatic parenchyma.

In accordance, the study of Sivalingam [41] showed that DEN induced necrosis. This liver necrosis which has been found 
in many of animals causes collapse of the paranchymal framework of the liver which can resemble fibrotic changes.

Also Reham et al., [33] demonstrated that administration of DEN induced morphological deformation in the liver pronounced with degeneration of hepatocytes and liver neoplastic cellular alteration.

With regard to the Saffron, The present study showed that the majority of cells which exhibited neoplastic suffered from apoptosis in the group of rats which treated by saffron.

Apoptosis or programmed cell death represents the regulated activation of a preexisiting death program encoded in the genome[42]. It is a highly orchestrated form of cell death and plays a central role in the control of tissue cell numbers in organ development ,homeostasis and normal functioning such as cell proliferation and differentiation[36].

This also can be explained by Susan [43] who reported that the groups of rats were treated with saffron have a significant reduction in the number and size of the nodules induced by DEN an large number of regular hepatocytes were observed.

Also , Sara [44] showed that livers of rats treated with crocin ( saffron) and $\mathrm{CCl}_{4}$ revealed better reservation of the normal liver architecture and rare generalized vacuolization of the cytoplasm of hepatocytes , with apparently normal nuclei very few inflammatory cells infiltration. Nicola et al., [45] reported that curcumin treatment to $\mathrm{HCC}$ rats models showed a considerable improvement in liver morphology. This confirms that saffron regulates multiple components of the cell death pathway driving the cancer cells towards apoptosis.

Generation of reactive oxygen species due to induction of HCC rat model may cause cytotoxicity associated with membrane phospholipids peroxidation, which is the basis for renal damage and necrotic renal cells.
Control group kidney showing normal renal tissue formed of numerous uniform round glomeruli and renal tubules, whereas DEN group kidney showing Focal interstitial nephritis manifested by aggregation of lymphocytes, macrophage in renal cortex besides fibroblast proliferation ,thickening of basement membrane of some glomeruli were seen treatment with saffron reduced most of the pathological alterations as a result of HCC model induction where in Saffron group kidney showing normal renal tubules lined by single layer of cuboidal epithelium with mild interstitial inflammation,

Our study is confirmed by Bandegia et al., [46] who indicated that chronic stressinduced oxidative stress damage of brain, liver and kidneys can be inhibited by saffron (crocin) due to the antioxidant effects, Crocin showed an antioxidative activity and decrement of lipid peroxidation levels in these organs[47]

\section{Conclusion:-}

In summary, the data presented here show that saffron dramatically inhibited the number and the incidence of hepatic nodules in livers of HCC rat model.This inhibition was associated with appearance of apoptosis, reduced cell proliferation, decreased oxidative stress and enhancement in total antioxidant capacity restoration of the TGF-beta level significantly restores the biochemical and hematological parameters to normal levels which revealed that the saffron extract is rich in antioxidant compounds, which clearly support the antioxidant and other related pharmacological properties including hepatoprotective activity

\section{References}

1- Ran Xu Zhu, Wai-Kay Seto,ChingLung Lai, and Man-Fung Yuen (2016): Epidemiology of Hepatocellular Carcinoma in the AsiaPacific Region. Gut Liver. May; 10(3): 332-339. 
2- Hashem B. El-Serag, MD, (2012): Epidemiology of Viral Hepatitis and Hepatocellular Carcinoma. Gastroenterol-ogy. May; 142(6): 12641273.e1.

3- Manal A Hamed and Sanaa A Ali (2013): Non-viral factors contributing to hepatocellular carcinoma. Published online Jun 27. doi: 10.4254/wjh.v5. i6.311. PMCID: PMC3692972. World J Hepatol. 2013 Jun 27; 5(6): 311-322.

4- Khalid Rahman (2007): Studies on free radicals, antioxidants, and cofactors. ClinInterv Aging. Jun; 2(2): 219-236.

5- S. Zahra Bathaie, Hamidreza Miri, Mohammad-Ali Mohagheghi, Manijeh Mokhtari- Dizaji, Amir-Ali Shahbazfar, and Hadi Hasanzadeh (2013): Saffron Aqueous Extract Inhibits the Chemically-induced Gastric Cancer Progression in the Wistar Albino Rat. PMCID: PMC3637902. Iran J Basic Med Sci. Jan; 16(1): 27-38.

6- Behjat Javadi, Amirhossein Sahebkar, and Seyed Ahmad Emami (2013): A Survey on Saffron in Major Islamic Traditional Medicine Books. PMCID: PMC3637900. Iran J Basic Med Sci. Jan; 16(1): 1-11.

7- Sahdeo Prasad and Bharat B. (2011): Aggarwal. Herbal Medicine: Biomolecular and Clinical Aspects. 2nd edition. From Traditional Medicine to Modern Medicine. Chapter 13, Turmeric, the Golden Spice

8- Mohammad Reza Khazdair, Mohammad Hossein Boskabady, Mahmoud Hosseini, Ramin Rezaee, and Aristidis M. Tsatsakis (2015): The effects of Crocus sativus (saffron) and its constituents on nervous system: A review. PMCID: PMC4599112. Avicenna J Phytomed. Sep-Oct; 5(5): 376-391.

9- Amr Amin, Alaaeldin A. Hamza, KhuloudBajbouj, S. Salman Ashraf, and Sayel Daoud (2011): HEPATOBILIARY Saffron: A
Potential Candidate for a Novel Anticancer. Drug Against Hepatocellular Carcinoma. HepatologyVolume 54, Issue 3,

10- Samuele De Minicis, Tatiana Kisseleva, Heather Francis, Gianluca Svegliati Baroni, Antonio Benedetti, David Brenner, DomenicoAlvaro, Gianfranco Alpini, and Marco Marzioni (2013): Liver carcinogenesis: Rodent models of hepatocarcinoma and cholangiocarcinoma. NIHMSID: NIHMS 494066. PMCID: PMC3716909. Published online $2012 \quad$ Nov 22. doi: 10.1016/j.dld.2012. 10.008. Dig Liver Dis. Author manuscript; available in PMC 2013 Jul 19. Published in final edited form as: Dig Liver Dis. Jun; 45(6): 450-459.

11- Young D.S. (2001): Effect of disease on clinical lab. Tests, 4th ed. AACC press.

12- Reitman, S. and Frankel, S. (1975): Colorimetric determination of glutamic oxaloacetic and glutamic pyruvic transaminase. Journal Clincal Pathology, 28-56.

13- Satoh, K (1978): Serum lipid peroxide in cerebrovascular disorders determined by a new colorimetric method. Clinic ChimicaActa., 90: 3743.

14- Koracevic D, Koracevic G, Djordjevic V, Andrejevic $S$ and Cosic V. (2001): Method for the measurement of antioxidant activity in human fluids.JClin Pathol; 54(5):356361

15- oki H, Ohnishi H, Hama K, Ishijima T, Satoh Y, Hanatsuka K, Ohashi A, Wada S, Miyata T, Kita $H$, Yamamoto $H$, Osawa $H$, Sato $K$, Tamada K, Yasuda H, Mashima H and Sugano K(2006) Am J Physiol Cell Physiol (290):11001108

16- Ali MM and Jesmin M (2010): Hepatotoxicity of Schiff bases derived from benzoin salicylaldehyde, 
aminoph-enol and 2,4dinitrophenyl hydrazine. J NatnSci Foundation Sri Lanka. 38(2): 145149

17- Levesque R SPSS (2007): Programming and Data Management: A Guide for SPSS and SAS Users, Fourth Edition SPSS Inc.Chicago.

18- "Adult Primary Liver Cancer Treatment (PDQ ${ }^{\circledR)}$ )-Patient Version" (2016): NCI. 6 July. Retrieved 29 September 2016.

19- Ali Kuraishy, Michael Karin, and Sergei I. Grivennikov (2011): Tumor Promotion via Injury- and Deathinduced Inflammation. PMCID: PMC3587290. NIHMSID: NIHMS331675.

doi: $\quad$ 10.1016/j.immuni.2011.09.006. Immunity. Oct 28; 35(4): 467-477.

20- Yohei Shirakami, Max E. Gottesman, and William S. Blaner (2012): Diethylnitrosamine-induced hepatocarcinogenesis is suppressed in lecithin:retinolacyltransferase-deficient mice primarily through retinoid actions immediately after carcinogen administra-tion. PMCID: PMC3271263. Published online 2011 Nov 24. doi: 10.1093/carcin/ bgr275. Carcinogenesis. 2012 Feb; 33(2): 268274.

21- Andrea J. Moreira, GraziellaRodrigues, Silvia Bona, Carlos ThadeuCerski, Claudio A. Marroni, Jose L. Mauriz, Javier González-Gallego, Norma P. and Marroni (2015): Oxidative stress and cell damage in a model of precancerous lesions and advanced hepatocellular carcinoma in rats. Toxicology Reports Volume 2, Pages 333-340

22- Antonio Ayala, Mario F. Muñoz, and Sandro Argüielles (2014): Lipid Peroxidation: Production, Metabolism, and Signaling Mechanisms of Malondiald-ehyde and 4-Hydroxy-2Nonenal. Oxidative Medicine and Cellular Longevity. http://dx.doi.org/
10.1155/ 2014/360438. Volume Article ID 360438, 31 pages

23- FemkeHeindryckx, Isabelle Colle, and Hans Van Vlierberghe (2009): Experimental mouse models for hepatocellular carcinoma research. PMCID: PMC2741148. doi: 10.1111/ j.1365-2613.2009.00656.x. Int $J$ ExpPathol. 2009 Aug; 90(4): 367-386.

24- H-X Yan, H-P Wu, H-L Zhang, C Ashton, C Tong, J Wu, Q-J Qian, H$Y$ Wang, and Q-L Ying (2013): DNA damage-induced sustained p53 activation contributes to inflammationassociated hepatocarcinogenesis in rats. PMCID: PMC3855850. NIHMSID: NIHMS533950. Published online $2012 \quad$ Oct 15. doi: 10.1038/onc.2012.451. Oncogene. Author manuscript; available in PMC 2013 Dec 7. Published in final edited form as: Oncogene. Sep 19; 32(38).

25- Fengyuan Li, Kangmin Duan, Cuiling Wang, Craig McClain, and Wenke Feng (2016): Probiotics and Alcoholic Liver Disease: Treatment and Potential Mechanisms. http://dx.doi.org/10.1155/2016/549146 5. Gastroenterology Research and Practice. Volume, Article ID 5491465, 11 pages.

26- Nouf Al-Rasheed, Laila Faddah, Iman A Sharaf, Azza M Mohamed, Nawal Al-Rasheed and NayiraAbdelbaky (2015): Assessment of the Potential Role of Silymarin Al one or in Combination with Vitamin E and/ or Curcumin on the Carbon Tetrachloride Induced Liver Injury in Rat. PMCID: 891320150232. ISSN 1516-8913 Printed in Brazil. ttp://dx.doi.org/10.1590/S1516.

Brazilian Archives Of Biology And Technology An international journal. December, Vol.58, n.6: pp. 833-842.

27- Ghada M.A. Ragab, Ezzeldeen S. ElDenshary, Aziza M. Hassan, Sekena H. Abdel-Azeim, Nabila S. Hassan, Fathia A. Mannaa and Mosaad A. Abdel-Wahhab (2013): Grape 
(Vitisvinifera) Seed Extract Inhibits the Cytotoxicity and Oxidative Stress in Liver of Rats Treated with Carbon Tetrachloride. ISSN 1992-0075. (C) IDOSI Publications, 2013. DOI: 10.5829/idosi.gjp.2013.7.3.7637.

Global Journal of Pharmacology 7 (3): 258-269, 2013

28- Ahmad Reza Gohari, SoodabehSaeidnia, and Mahdie Kourepaz Mahmoodabadi (2013): An overview on saffron, phytochemicals, and medicinal properties. PMCID: PMC3731881. doi: $\quad 10.4103 / 0973-7847.112850$. Pharmacogn Rev. 2013 Jan-Jun; 7(13): 61-66.

29- Cui-Li Zhang, Tao Zeng, Xiu-Lan Zhao, Li-Hua Yu, Zhen-Ping Zhu and Ke-Qin Xie (2012): Protective Effects of Garlic Oil on Hepatocarcinoma Induced by $\mathrm{N}$ Nitrosodiethylamine in Rats. doi:10.7150/ijbs.3796. Int J BiolSci; 8(3):363-374.

30- Claudio Festuccia, Andrea Mancini, Giovanni Luca Gravina, Luca Scarsella, Silvia Llorens, Gonzalo L. Alonso, Carla Tatone, Ernesto Di Cesare, Emmanuele A. Jannini, Andrea Lenzi, Anna M. D'Alessandro, and Manuel Carmona (2014): Antitumor Effects of SaffronDerived Carotenoids in Prostate Cancer Cell Models. http://dx.doi.org/10.1155/2014/135048. BioMed Research International. Volume 2014, Article ID 135048, 12 pages

31- Sha Li, Hor-Yue Tan, Ning Wang, Zhang-Jin Zhang, Lixing Lao, ChiWoon Wong, and Yibin Feng (2015): The Role of Oxidative Stress and Antioxidants in Liver Diseases. PMCID: PMC4661801. Published online $2015 \quad$ Nov 2. doi: 10.3390/ijms161125942. Int J Mol Sci. Nov; 16(11): 26087-26124.

32- Tawfik Khoury, Ayman Abu Rmeileh, Liron Yosha, Ariel A.
Benson, Saleh Daher, and Meir Mizrahi (2015): Drug Induced Liver Injury: Review with a Focus on Genetic Factors, Tissue Diagnosis, and Treatment Options. PMCID: PMC4548351. Published online 2015 Jun 15. doi: 10.14218/JCTH.2015.00007. J Clin Transl Hepatol. 2015 Jun 28; 3(2): 99-108.

33- Reham H. Mekky, Mostafa R. Fayed, Mohamed R. El-Gindi, Azza R. Abdel-Monem, María del Mar Contreras, Antonio SeguraCarretero, and Essam Abdel-Sattar (2016): Hepatoprotective Effect and Chemical Assessment of a Selected Egyptian Chickpea Cultivar. PMCID: PMC5040119. Published online 2016 Sep 28. doi: 10.3389/fphar. 2016.00344. V.7: P.344.

34- Edoardo G. Giannini, Roberto Testa, and Vincenzo Savarino (2005): Liver enzyme alteration: a guide for clinicians. PMCID: PMC545762.

doi: 10.1503/cmaj.1040752. CMAJ. 2005 Feb 1; 172(3): 367-379.

35- Moustafa AH, Ali EM, Moselhey SS, Tousson E and El-Said KS (2014): Effect of coriander on thioacetamideinduced hepatotoxicity in rats. doi: 10.1177/0748233712462470.

Aug;30(7):621-9.

36- A. Nasir, M.G. Abubakar, R.A. Shehu, U. Aliyu, and B.K. Toge (2013): Hepatoprotective Effect of the Aqueous Leaf Extract of And rographispaniculata Nees Against Carbon Tetrachloride - Induced Hepatotoxicity in Rats. ISSN 07945698. DOI: http://dx.doi.org/ 10.4314/njbas.v21i1.7. Nigerian Journal of Basic and Applied Science (March, 2013), 21(1): 45-54

37- Cengiz Bolukbas, Fusun F Bolukbas, Tevfik Sabuncu, Mehmet Aslan, Serpil Sarifakiogullari,

Necla Gunaydin and Ozcan Erel (2005): Measurement of the total 
antioxidant response using a novel automated method in subjects with nonalcoholic steatohepatitis. DOI: 10.1186/1471-230X-5-35. Horoz et al; licensee BioMed Central Ltd. 2005. BMC Gastroenterology, 5:35

38- Joan Massagué (2008): TGF $\beta$ in Cancer. PMCID: PMC3512574. NIHMSID: NIHMS412481. doi: 10.1016/j.cell. 2008.07.001. Cell. 2008 Jul 25; 134(2): 215-230.

39- Rosemary J. Akhurst and Akiko Hata (2012): Targeting the TGF $\beta$ signalling pathway in disease. PMCID: PMC3520610. NIHMSID: NIHMS421715. Published online 2012 Sep 24. doi: 10.1038/nrd3810. Nat Rev Drug Discov. Oct; 11(10): 790811.

40- Hye Jung Baek, Sung Chul Lim, Krit Kitisin, Wilma Jogunoori, Yi Tang,M. Blair Marshall, Bibhuti Mishra, Tae Hyun Kim, Kwan Ho Cho, Sang Soo Kim, and Lopa Mishra (2008): Hepatocellular Cancer Arises from Loss of Transforming Growth Factor Beta Signaling Adaptor Protein Embryonic Liver FodrinThrough Abnormal Angiogenesis. PMCID: PMC2747753. NIHMSID: NIHMS115900. doi: 10.1002/hep.22460. Hepatology. Oct; 48(4): 1128-1137.

41- Sivalingam Murugan, Ameesh Madhusoodanan Nair, Shilpa Shankar, and Vishal Babu (2015): Study on the Anticarcinogenic Efficacy of Withaferin-Ain DEN Induced Hepatocellular Carcinoma: Morphology and Histopa-thology. International Journal of Health Sciences \& Research (www.ijhsr.org). Vol.5; Issue:9; September. 273-282

42- Liam Portt, Grant Norman, Caitlin Clapp, Matthew Greenwood and Michael T. Greenwood (2011): Antiapoptosis and cell survival: A review. BiochimicaetBiophysicaActa (BBA) Molecular Cell Research. Volume 1813, Issue 1, January, Pages 238-259
43- Susan Elmore (2007): Apoptosis: A Review of Programmed Cell Death. PMCID: PMC2117903. NIHMSID: NIHMS33547. Published in final edited form as: doi: 10.1080/ 01926230701320337. Toxicol Pathol. Author manuscript; available in PMC 2007 Dec 6. 35(4): 495-516.

44- Sara S. Al Disi, M. Akhtar Anwar, and Ali H. Eid (2015): Antihypertensive Herbs and their Mechanisms of Action: Part I. PMCID: PMC4717468.

doi: 10.3389/fphar.2015.00323. 2015; 6: 323 .

45- Nicola Bortel, Sorin ArmeanuEbinger, Evi Schmid, Bettina Kirchner, Jan Frank, Alexa Kocher, Christina Schiborr, Steven Warmann, Jörg Fuchs, and Verena Ellerkamp (2015): Effects of curcumin in pediatric epithelial liver tumors: inhibition of tumor growth and alpha-fetoprotein in vitro and in vivo involving the NFkappaB- and the betacatenin pathways. PMCID: PMC4747361. Published online 2015 Oct

19. doi: 10.18632/oncotarget.5673. Dec 1; 6(38): 40680-40691.

46- Bandegi AR, Vafaei Abbas A, Ghaderdoost B and Rashidy-Pour A. (2014): Protective effects of Crocus sativus L. extract and crocin against chronic-stress induced oxidative damage of brain, liver and kidneys in rats. Adv Pharm Bull. 4:493-499.

47-Rajaei Z, Hadjzadeh MAR, Nemati $H$, Hosseini $M$, Ahmadi $M$ and Shafiee S. (2013): Anti hyperglycemic and antioxidant activity of crocin in streptozotocin-induced diabetic rats. Way J Med Food. 16:206-210 
Table (1): ALT and AST activity and Albumin serum level in control, DEN and saff. groups

\begin{tabular}{|l|c|c|c|c|}
\hline & Control & DEN & Saff. & P-value \\
\hline \hline ALT $(\mathrm{U} / \mathrm{ml})$ & $42.33 \pm 4.16$ & $309.67 \pm 79.97$ & $221.66 \pm 37.75$ & $<0.001$ \\
\hline AST $(\mathrm{U} / \mathrm{ml})$ & $132.83 \pm 9.37$ & $542.67 \pm 88.71$ & $405.67 \pm 40.1$ & $<0.001$ \\
\hline Albumin $(\mathrm{mg} / \mathrm{dl})$ & $4.32 \pm 0.07$ & $3.63 \pm 0.1$ & $3.56 \pm 0.12$ & $<0.001$ \\
& & & & \\
\hline
\end{tabular}

Table ( 2): TAC and TGF-beta serum level in control, DEN and saff. groups

\begin{tabular}{|l|c|c|c|c||}
\hline & Control & DEN & Saff. & P-value \\
\hline \hline TAC $(\mu \mathrm{m} / \mathrm{ml})$ & $115.1 \pm 5.4$ & $28.58 \pm 1.82$ & $64.13 \pm 3.41$ & $<0.001$ \\
\hline TGF-beta(ng/ml $)$ & $28.46 \pm 1.59$ & $171.1 \pm 6.7$ & $69.85 \pm 3.0$ & $<0.001$ \\
\hline
\end{tabular}

$(\mathrm{U} / \mathrm{ml})$

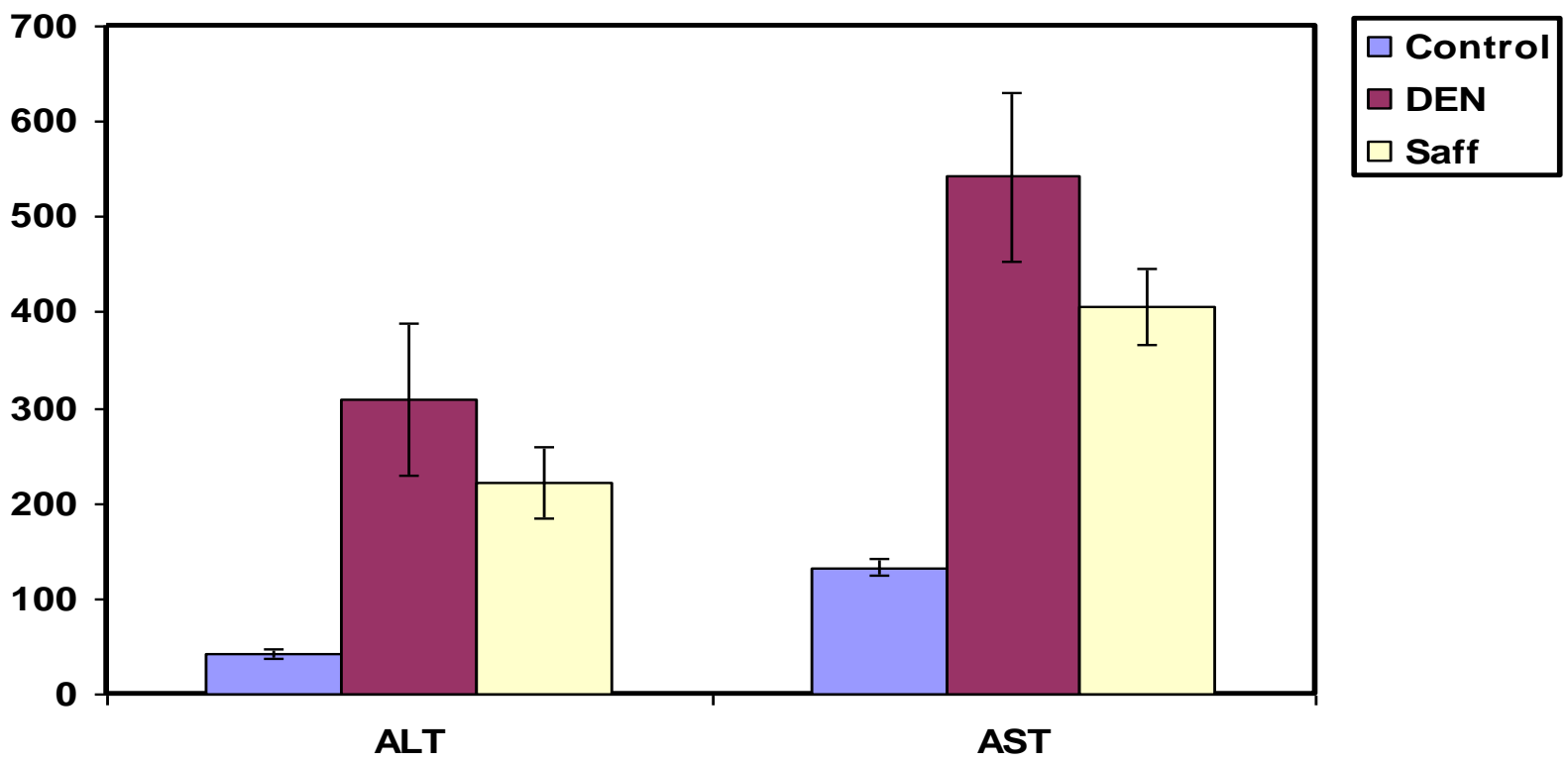

Figure (1) ALT and AST activity in control, DEN and saff. groups 
$(\mathrm{mg} / \mathrm{dl})$

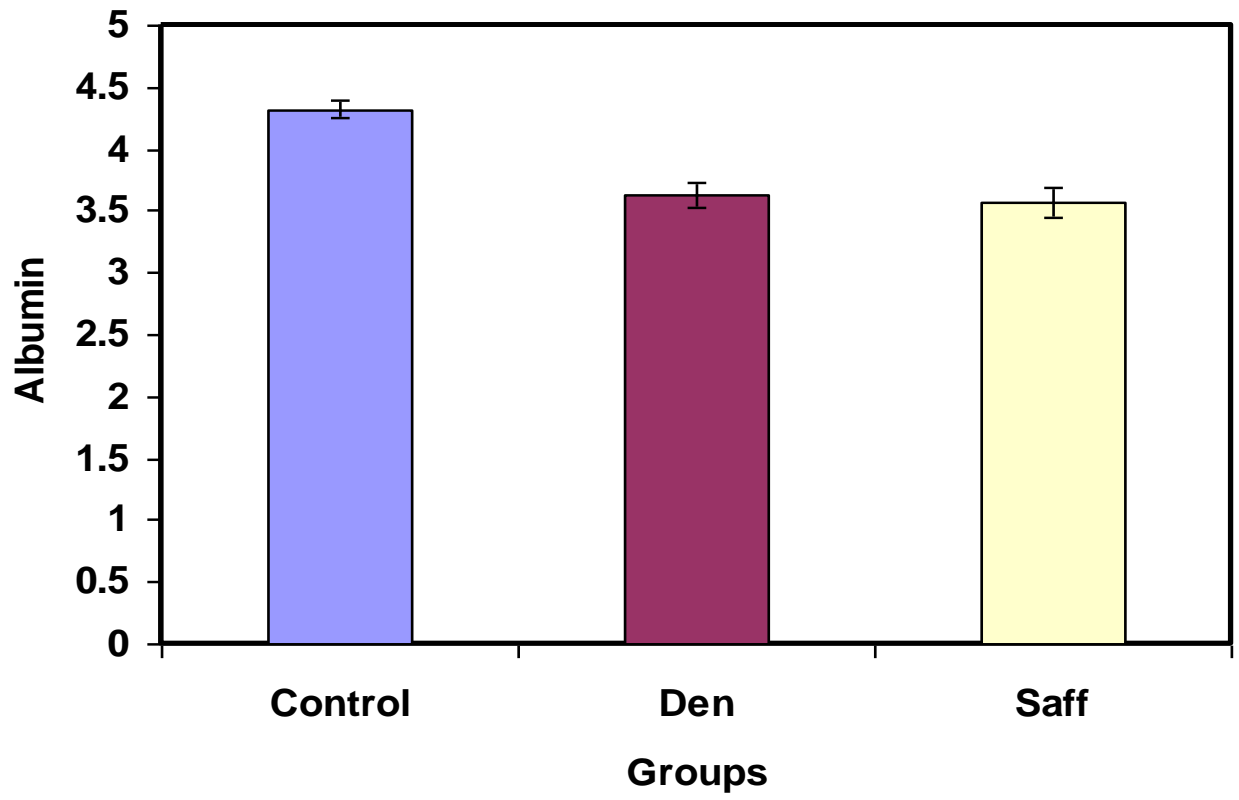

Figure (2) albumin serum level in (control, DEN and saff.) groups

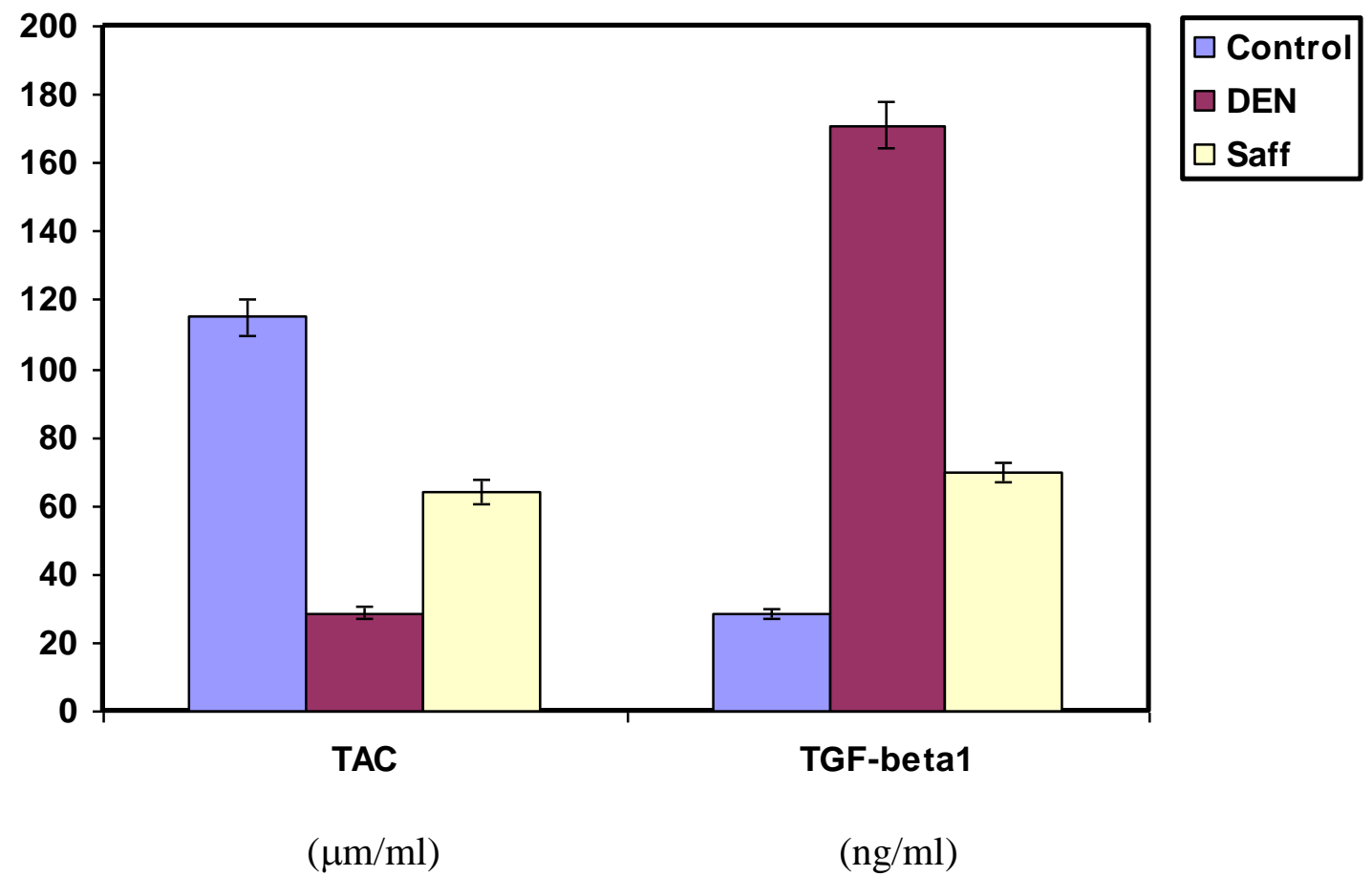

Figure (3) TAC and TGF-beta serum level in control, DEN and saff. groups 
Table ( 3): Different hematological parameters in control, DEN and saff. groups

\begin{tabular}{|l|c|c|c|c|}
\hline & Control & DEN & Saff. & P-value \\
\hline \hline $\mathrm{Hb}$ g/dl & $15.36 \pm 0.41$ & $11.40 \pm 1.6$ & $14.38 \pm 0.26$ & $<0.001$ \\
\hline RBCs $* 10^{6} / \mu \mathrm{L}$ & $8.16 \pm 0.18$ & $6.9 \pm 0.70$ & $7.80 \pm 0.23$ & $<0.001$ \\
\hline WBCs $* 10^{3} / \mu \mathrm{L}$ & $19.36 \pm 2.19$ & $25.88 \pm 8.50$ & $21.33 \pm 3.07$ & $<0.001$ \\
\hline Platelets*10 $10^{3} / \mu \mathrm{L}$ & $845.66 \pm 38.21$ & $692.67 \pm 78.57$ & $720.63 \pm 42.02$ & $<0.001$ \\
\hline & & & & \\
\hline
\end{tabular}

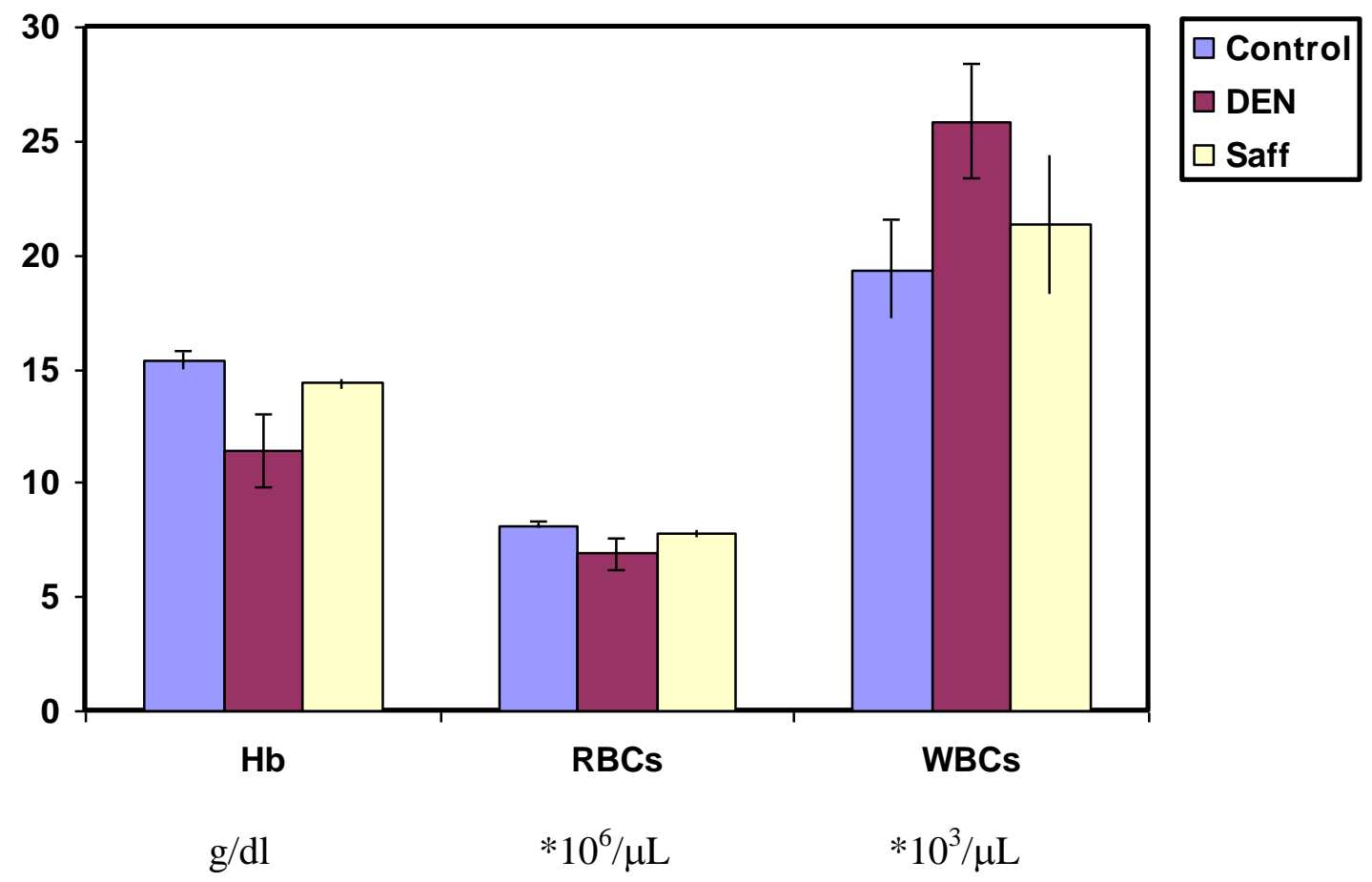

Figure (4)Different hematological parameters in (control, DEN and saff.) groups 
Platelet count $* 10^{3} / \mu \mathrm{L}$

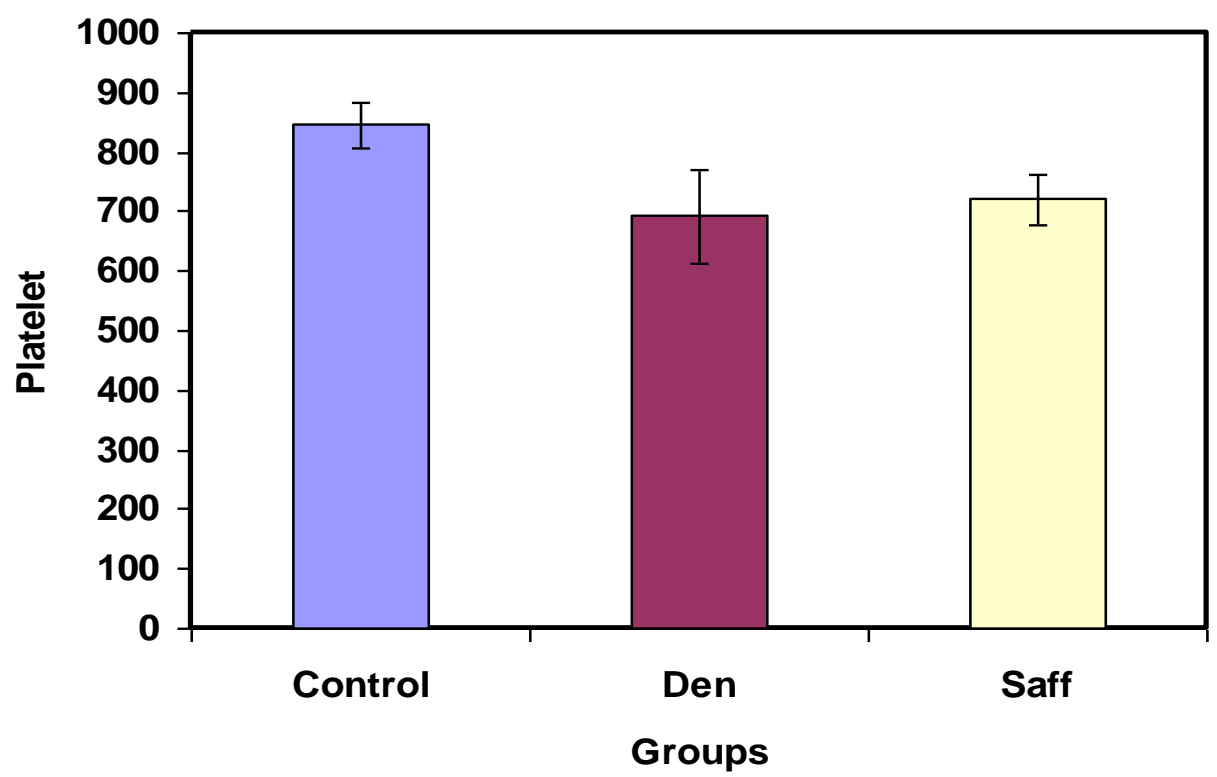

Figure (5)Platelet count control, DEN and saff. groups

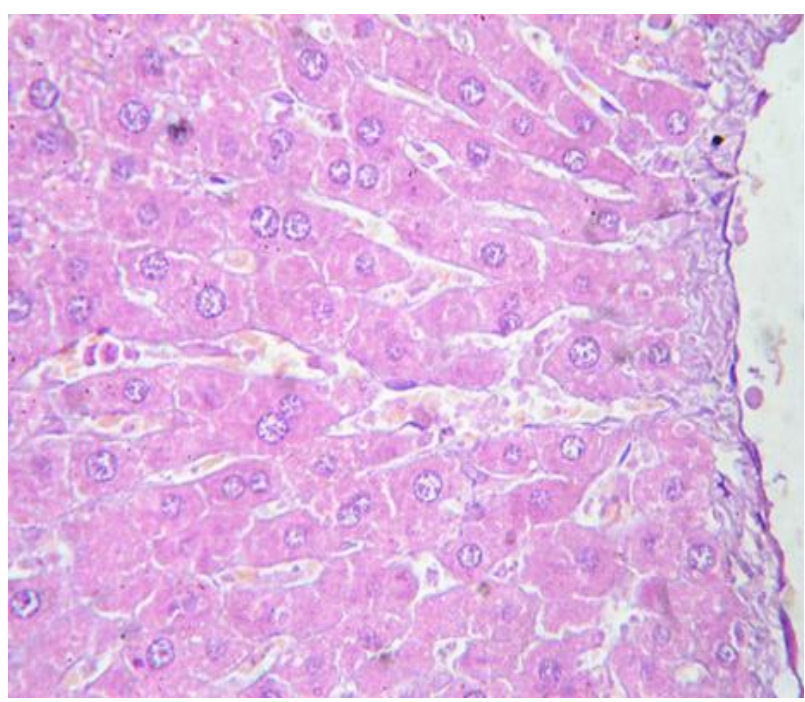

Figure 6: Liver of control rats showing normal hepatic parenchyma, normal hepatic cells cords and sinusoids. $\mathrm{H} \& \mathrm{E}(\mathrm{X} 300)$.

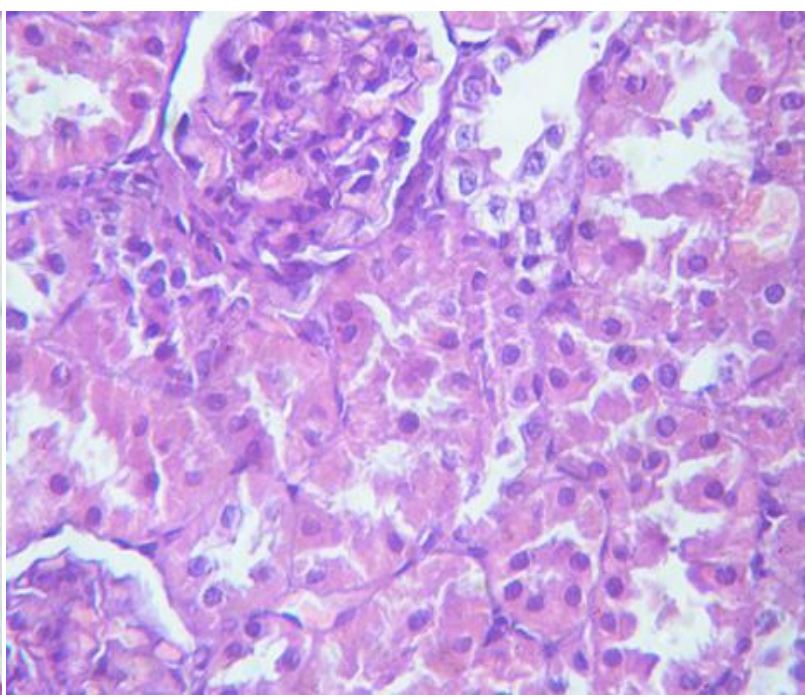

Figure 9: Kidney of control rats showing normal renal glomeruli and renal tubules. H\&E(X1200). 


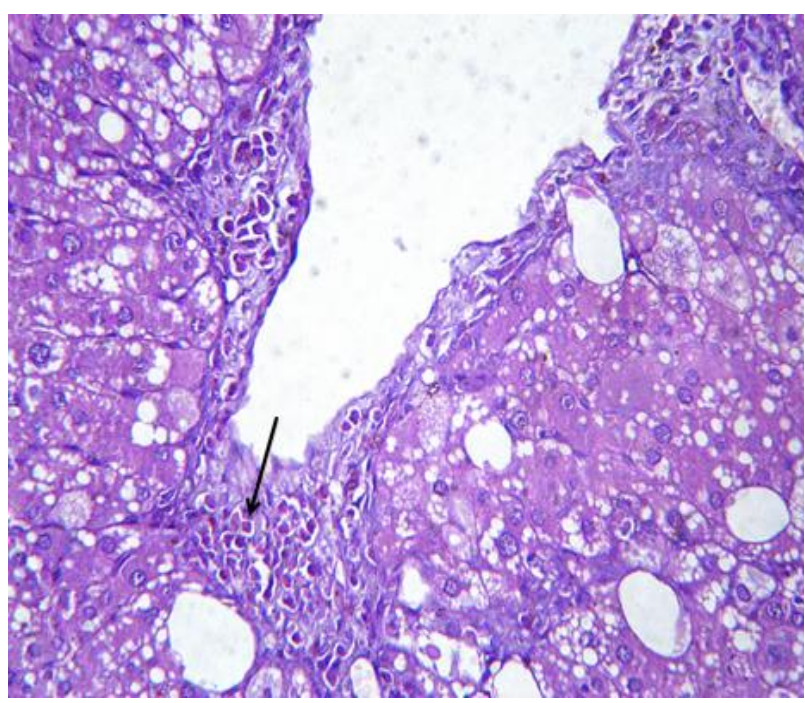

Figure 7 Liver of rat DEN group showing numerous neutrophils and mononuclear cells within the vascular wall (arrow) together with perivascular fibrosis and diffuse fatty changes (steatosis) of the hepatic cells. $\mathrm{H} \& \mathrm{E}(\mathrm{X} 1200)$.

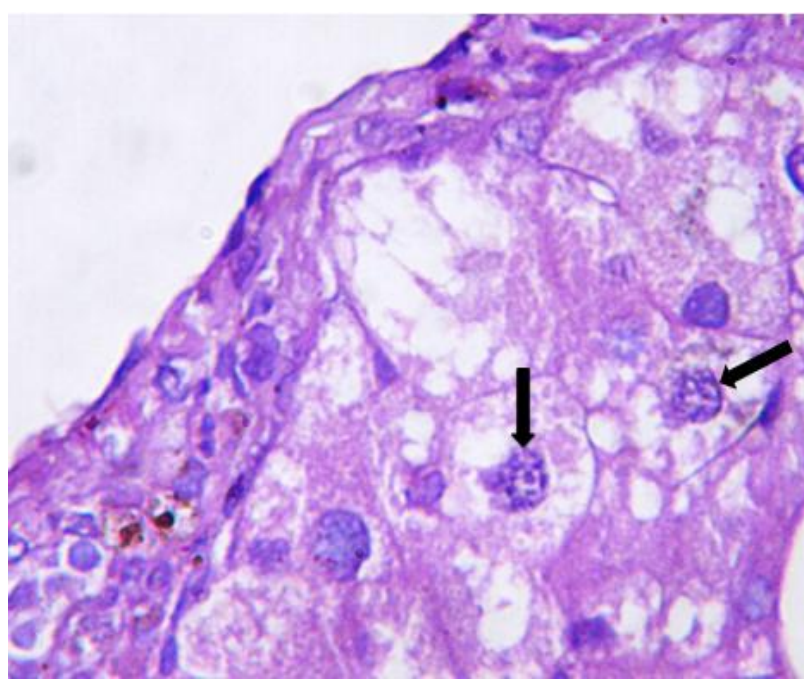

Figure8:Liver of saff. group showing apoptotic nuclei (arrow).

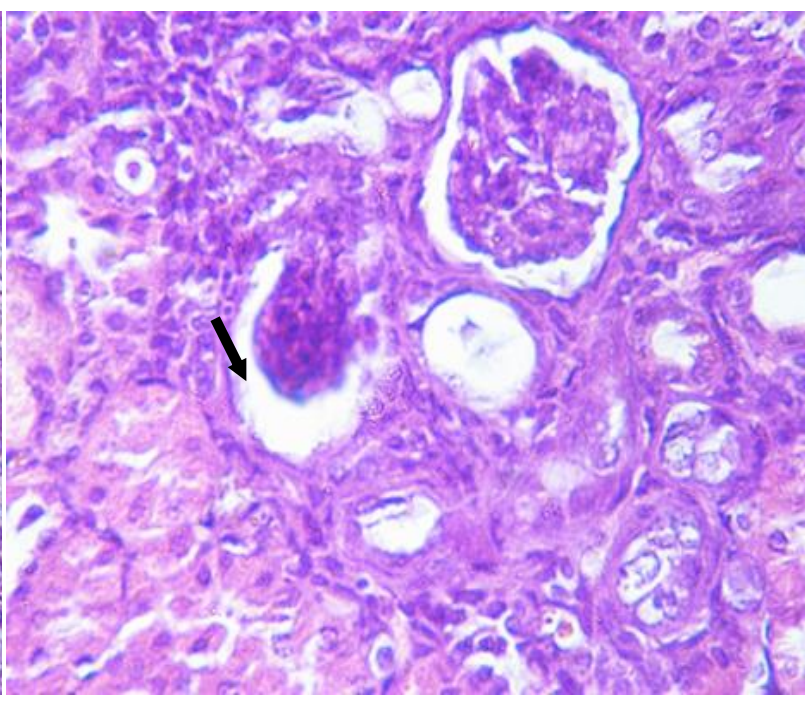

Figure 10: Kidney of rat (DEN)showing thickening of basement membrane of some glomeruli. Focal necrosis of tubular epithelium and regeneration attempts. H\&E (X1200).

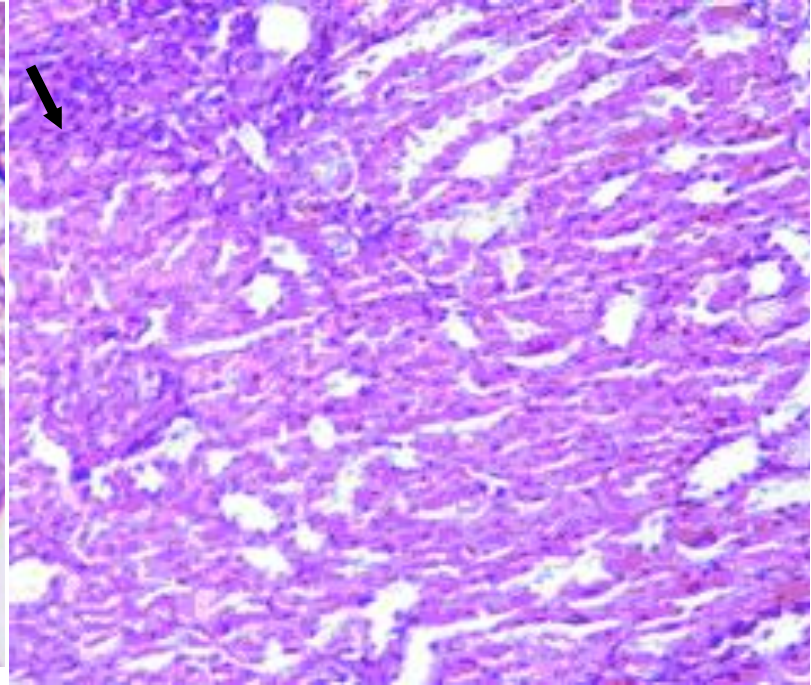

Figure11: Kidney of saff. Group showing focal interstitial nephritis 